РЕЗНИК Оксана Владимировна доктор филологических наук, профессор, заведующая кафедрой библиотечно-информационной деятельности

и межъязыковых коммуникаций Крымского университета культуры, искусств и туризма Симферополь, Российская Федерация Oksana V. REZNIK Dr. Sci. (Russian Literature), Prof., Crimean University of Culture, Arts and Tourism, Simferopol, Russian Federation, oreznik200@yandex.ru

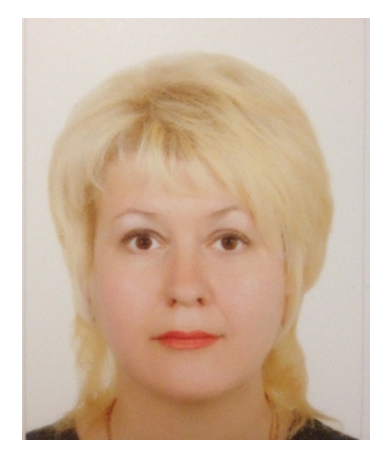

УДК: [173.7:124.5]:821.161.1"20"

DOI: 10.36343/SB.2021.28.4.005

ГРНТИ: 13.11.25

ВАК: 24.00.01

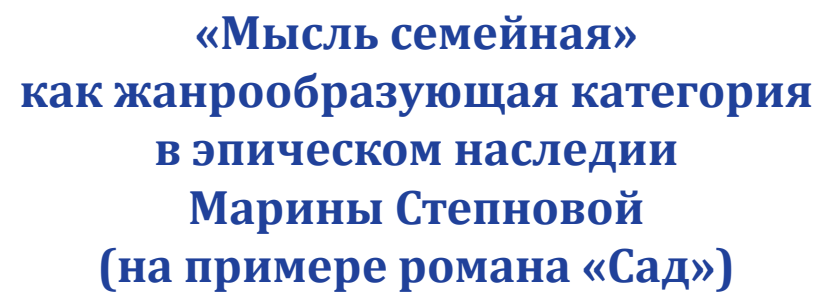
"Family Thought"
as a Genre-Forming Category in the Epic Heritage of Marina Stepnova (on the Example of the Novel Garden)

Статья призвана выявить специфику раскрытия семейной темы в романе Марины Степновой «Сад». Проанализирован текст произведения, рассмотрены результаты исследований современных отечественных литературоведов. Проблема взаимоотношений между супругами и между представителями различных поколений в семье решается М. Степновой на материале истории рода Борятинских и поместья Анна. Изучены образы романа, выделены произведения, которые цитируются или вводятся в контекст художественного пространства. М. Степнова создает исторический фон, сочетает эмоциональное описание пейзажей с прямой речью главных и второстепенных персонажей. В исследовании подчеркивается особый характер лирических отступлений, переводящих наррацию в романтическое русло. Автор статьи заключает, что изображение семьи Борятинских и судьбы России как сада, пережившего и расцвет, и изобилие, и постепенный упадок вплоть до уничтожения, позволяет определить роман М. Степновой как семейную хронику

Ключевые слова: семейная хроника, сад, российское мироустройство, тема семьи, дворянство, индивидуальность, исторический контекст, русская литература XXI века.

Современная литература ввела в начале XXI века достаточно большое количество тем впервые, демонстрируя модернистскую направленность в различных аспектах твор- чества. Тема взаимоотношений между поколениями и супругами к ним не относится, так как уже рассматривалась и в творчестве В. Распутина, В. Астафьева, Т. Толстой. Л. Пет- 
рушевской, и в произведениях более раннего периода, XIX - первой половины XX века. Раскрывая данный аспект, писатель не только концентрирует внимание читателя на психологических проявлениях взаимоотношений, а в большей или меньшей степени демонстрирует диалог личности и социума. Актуальность данного исследования обусловлена тем, что роман Марины Степновой «Сад» является образцом неореализма и презентационной формой современной художественной практики. Появление жанра семейной саги в культуре двухтысячных свидетельствует о модернизации социального запроса. С другой стороны, именно сочетание семейной и исторической линий говорит о сформировавшихся в определенных читательских кругах коммуникационных и выразительных предпочтениях. Исследователи О. М. Мякинина и И. А. Шитуева отмечают: «Сложные, неоднозначные события рубежа XX-XXI вв. усилили ощущение трагизма, иллюзорности семейных ценностей...» [1, с. 40]. М. Степнова не в первый раз обращается к поликомпонентному сюжету («Женщины Лазаря»), который на примере нескольких семей и поколений демонстрирует взаимообусловленность истории и личностного пути.

Творчество Степновой, представляющее собой ряд эпических произведений, характерно для России конца XX - начала XXI вв. В ходе изучения русскоязычных научных работ о современном литературном процессе обнаруживается, что предметом внимания литературоведов художественные тексты данного автора стали относительно недавно и не все их аспекты проанализированы достаточно полно. В то же время тема семейных ценностей и взаимоотношений, столь важная для представителей современной литературы (о чем свидетельствуют публикации О. М. Мякининой и И.А. Шитуевой [1], И. Б. Ничипорова [2], О.Ю. Осьмухиной, А. В. Казачковой [3] [4] и др.), в романе 2019 года «Сад»как ключевая не представлена. Поэтому в исследовании будет использовано понятие «семейная тема» в контексте осмысления романных характеристик, а понятие «семейная сага» - для обозначения жанра произведения, пошедшего по пути синтеза семейной и исторической линий.
Новизна работы определяется отсутствием комплексного исследования по осмыслению семейной темы в эпическом наследии Степновой как сюжетной и жанрообразующей доминанты. Наше исследование будет способствовать более глубокому и всестороннему раскрытию механизмов трансформации человеческих взаимоотношений в эпоху модернизации культуры и социума, так как жанр семейной саги (хроники) представлен и в других произведениях современной литературы (например, «Ложится мгла на старые ступени» Александра Чудакова). Как отмечает Е.С.Седашова, «семейная хроника - это особый тип прозы, который обладает индивидуальными чертами: проблематикой, спецификой историзма, особенностями хроникального построения. Этот жанр пользуется большой популярностью у читателей и имеет длинную предысторию, является одним из перспективных в массовой литературе» [5, с. 82]. Таким образом, цель данной публикации - проследить специфику реализации семейной темы в романе М. Степновой «Сад» [6].

В процессе исследования, осуществленного с опорой на текст анализируемого произведения и с привлечением работ современных отечественных литературоведов, были применены методы литературной герменевтики, интертекстуального анализа, а также сравнительно-исторический и структурный методы.

В романе Степновой «Сад» сразу, с заголовка, начинается игра с читателем. Употребленное без эпитетов нарицательное «сад» вызывает самые разные ассоциации - от «Вишневого сада» Чехова до сада камней. Такая полисемантика сохраняется и на протяжении всего текста. Основная задача автора - показать судьбу страны через судьбы персонажей - легко читается, а главное - выполняется на протяжении практически линейного сюжета. Опережающие или ретардирующие вставки на лирическую или историческую тему не прерывают сюжет, а, скорее, интенсифицируют композицию, соединяют различные тематические пласты. Выбирая название имения - Анна, Степнова задает символику древнееврейскую и христианскую: название-имя переводится и как «благосклонность» 
или «расположение», и как «милость» или «милосердие» [7, р. 41].

Наррация идет через изображение судьбы рода Борятинских, их первая встреча с садом и последняя - вырубка под пастбища практически создают рамку, меняя пафос романа. Если в первой картине доминирует изображение изобилия, роскоши, «невиданные кущи», ассоциативно связанные с Эдемом, то в финале - простор и свобода, подчиненность воле человека. «Новый и старый сад вырубили полностью. Парк тоже». Как свободен всякий, не знающий, что готовит ему будущее, так изображена новая хозяйка земли - Туся.

Еще один знаменательный прием изменение роли мужского и женского начала. В паре - князь и княгиня - доминирует женское начало. Именно княгиня выберет, где жить и как жить дальше. Их брак был просчитан родителями, авторская ремарка «не прогадали». Причина изменений - сад, к которому употреблен авторский эпитет «через край выпирающий, почти непристойный», выступающий как контраст к обыденной супружеской жизни.

В начале романа сад представлен как праздник - «нескончаемый, щедрый, торжествующий», убедительное ликование божественной плоти [6, с. 20]. Простота и разумность устройства сада сравнивается с револьвером. Читается аллюзия на «Другие берега» В. В. Набокова - автора, никогда не знавшего Борятинских. Сочная слива уподобляется смокве из другого литературного источника, отсылая к образу Суламифи. Автор подчеркивает не только богатство сада, но и роскошь всей семьи - громадной и пронизанной родственным чувством, такой же взаимообусловленной, как «российское мироустройство». Определяющие черты народа в свежекупленном имении - невежество и лень, что также выстраивает ассоциативный ряд с «Обломовым» И. А. Гончарова.

Княгиня Надежда Александровна Борятинская - одна из центральных персонажей романа. На ней держится сюжетная линия: она покупает сад и имение Анна, она хочет нового в отношениях с мужем, результатом чего становится рождение нежелательной для князя поздней дочери, она возвращает врача Мейзе- ля и отправляет его с Тусей в столицу за счастьем. Героиня с говорящим именем (достаточно вспомнить «Темные аллеи» И.А.Бунина) охарактеризована как женщина, которая любит прекрасное вокруг себя. Решающим фактором для нее становится принцип художественной гармонии, раскрываемый автором на протяжении всей наррации в ряде выразительных примеров. Объяснением этого принципа становится упрощенная бытовая особенность - в основе такого поведения лежит брезгливость к грязи, уродству.

Княгиня упрямо поступает по-своему, воспринимая жизнь как подобие мозаики Ломоносова. Ее поздняя беременность разрушила привычный публичный мир, стройный и понятный для большинства. Мейзель спас ее от самоубийства, от возможного сумасшествия, а сад помог налиться «сытой сонной спелостью» [6, с. 88]. Эта аллитерация подчеркивает своеобразие героини, создавая новый типаж, антонимичный образу князя «с волчьими от обиды глазами». Все, что у нее оставалось,- ребенок и сад. Эта пара, неразделимая и отрадная, становится определяющей практически до смерти княгини. Появившаяся воспитанница Нюта и зять фрагментарно встраиваются в эту картину, но не занимают в ней значимого места. Выступает как показатель свободы и русский язык, на котором в большинстве своем стали говорить в этом имении, потому что французский не был настолько живым и напористым способом коммуникации, насколько требовала того обстановка имения с таким звучным названием. Изменения, произошедшие в отношениях семьи Борятинских, также выражаются на языковом уровне через возвращение к привычному и равнодушному приветствию князя на французском языке, обилию в речи иностранных терминов (турнюр, кринолин и др.).

Главной причиной семейного разлада, связанного в том числе с постепенным уходом князя, биологического отца ребенка, из жизни семьи, замещения его места врачом, становится поздняя дочь Туся, Наташа, названная в честь героини романа Льва Толстого. Долгое время она молчит, выражая свой характер жестами, мимикой, криками, первые ее слова были сказаны на конюшне. 
Такая своеобразная коммуникация делает данный образ типологически универсальным и ярко индивидуальным. С его появлением в романе возникает настолько активная линия наррации, связанная с лошадьми, что уже в середине романа возникает убеждение, что название «Конюшня» более удачно подходит для произведения. Туся поступает так, как ей хочется, она преодолевает стереотипы, хотя некоторое время безуспешно пытается вписаться в высшее общество, как мечтает ее мать и родственники. После возвращения в Анну она оттесняет на периферию не только соперницу - воспитанницу княгини, но и свежеобретенного супруга, и даже княгиню и Мейзеля.

Еще один персонаж - Григорий Иванович Мейзель, врач, личность одинокая и пережившая несколько душевных сломов, лютеранского вероисповедания, в котором князь слышит «что-то раздражающе нерусское». На протяжении книги мы узнаем и о его родословной со времен Ивана Грозного, и о его любви к даме легкого поведения, которая не питала ответных чувств из-за медицинского профиля их отношений, и о его участии в холерном бунте, и об изгнании из имения Анна и возвращении туда практически в качестве отца новорожденной Туси. На примере Мейзеля автор показывает личность с сильным характером, типологически связанную с героями Л.Н.Толстого и Г. Ибсена. Финал, осуществленный Григорием Ивановичем, отличается от финала настоящего, биологического отца, который уйдет из жизни маргинально, вне сюжетной линии. Он способствует появлению юной героини - но в последний момент будет замена, он заставит ее заговорить - но она скажет не те слова, он будет воспитывать новую личность - но ей не дадут нового образования и сам он в значительной степени потеряет свое влияние на эту хозяйку имения.

Отдельная страница - Борятинскиемладшие, Николай и Лиза. Сын, служивший в армии, строгий, сумевший устроить свою судьбу, и дочь, вышедшая замуж за дипломата, разъезжающая по Европе и бьющая по щекам прислугу. Образы эпизодические, но очень значимые. Они оба дают негативную оценку имению, не видят в нем никаких перспектив, а к княгине не испытывают близких, родственных чувств, характеризуя ее положение в роли матери новорожденного ребенка словами «стыд и мерзость». Необходимо отметить, что ответные чувства Надежды Александровны далеки от родительских - она удивилась пребыванию в ее доме этих красивых, взрослых и совершенно чужих людей. Несмотря на то, что старшие дети семьи выступают как эпизодические персонажи, они красноречиво демонстрируют неактуальность появления поздней ветви рода - их младшей сестры Туси.

Особого упоминания заслуживают лирические отступления, переводящие наррацию в романтическое русло. Один из эпизодов - приход смерти в дом - вызывает почти сказочную ассоциацию со «Спящей красавицей». Рассуждения о том, что мучит не смерть, а жизнь, продолжатся в эпизодах, рассказывающих о судьбе доктора, об охлаждении супружеских отношений, в истории о визите Натальи (Туси) Борятинской к доктору. Другое отступление - о смертности сельских детей, перекликающееся в воспоминаниях Мейзеля со сценой болезни юной княгини,- отличается практически публицистической направленностью и отсылкой к образу Наташи Ростовой из «Войны и мира» Л.Н. Толстого. Такие примеры позволяют выделить один из художественных приемов Марины Степновой - корреляцию изображаемого с концептами и символами ставших классическими произведений культуры. Так, описывая уход Мейзеля из дома Борятинских, она трижды повторяет уже ставшее афористичным выражение из «Трех сестер» А. П. Чехова: «В Москву!».

Также следует отметить пространные внутренние монологи героев, переходящие в общую наррацию. Автор сочетает эмоциональное описание пейзажей и ситуативное рассуждение с прямой речью как главных, так и второстепенных персонажей, прослеживая их судьбу практически до смерти.

При этом Степнова подробно описывает исторический контекст происходящего - в поле ее внимания попадают события холерного бунта, деятельность террористической фракции «Народная воля», Бестужев- 
ские курсы. Она не просто вводит в наррацию какой-либо значимый факт, а подробно датирует, например, зенит безмолвия Туси - лето 1875 г. или гибель пращура Мозеля летом от Рождества Христова тысяча пятьсот семьдесят девятого, вводя элемент эпичности, нивелируемый чрезмерно подробными дескрипциями. Подобные отступления свидетельствуют о тяготении жанровой природы данного произведения к роману-эпопее, о новых аспектах семейной хроники XXI в.
Следует отметить, что изображение семьи Борятинских и судьбы России как сада, пережившего и расцвет, и изобилие, и постепенную деградацию, катастрофичность, позволяет выделить роман М. Степновой как перспективное явление. Введением исторических фигур и событий (Александр III, семья Ульяновых, Бланк, холерный бунт) автор раздвигает рамки жанра семейной хроники, вызывая у читателя воспоминания об исторических трансформациях новой эпохи.

Oksana V. REZNIK

Dr. Sci. (Russian Literature), Prof., Crimean University of Culture, Arts and Tourism, Simferopol, Russian Federation, oreznik200@yandex.ru

\section{"Family Thought" as a Genre-Forming Category in the Epic Heritage of Marina Stepnova (On the Example of the Novel Garden)}

Abstract. The article aims to reveal the specifics of the implementation of the family theme in the novel Garden by the Russian writer Marina Stepnova. The research is based on the text of the novel and works of modern Russian literary scholars. Methods of literary hermeneutics, intertextual analysis, as well as comparative historical and structural methods were applied in the course of the research. The main and secondary images are analyzed; works cited or introduced into the context of the romantic space are identified. The problem of relationships between different generations and spouses in the family is solved in the novel based on the history of the Boryatinsky family and the Anna estate. The first meeting of the Boryatinskys with the garden and the last - cutting it down for pastures - practically create a chronological framework within which the pathos of the novel changes. The presence in the text of numerous insertions of an advancing or retarding character, connecting various thematic layers, is indicated. The writer seeks to demonstrate the constant change in the role of masculine and feminine principles in storylines as they develop. The technique by which the author of the novel combines an emotional description of landscapes and situational reasoning with the direct speech of the main and secondary characters is revealed. The special character of lyrical digressions, which translate the narration into the mainstream of the romantic style, is emphasized. The author of the novel often correlates the depicted with the images and symbols that appear in the works of the classics of Russian literature (A.P. Chekhov, L.N. Tolstoy, etc.). Tracing the fate of her heroes almost to death, Stepnova describes in detail the historical context of what is happening and gives an exact dating of the events. This feature, inherent mainly in the genre of the epic novel, testifies to new aspects of the family chronicle of the 21st century. The author of the article concludes that the portrayal of the Boryatinsky family and the fate of Russia as a garden that has experienced flourishing, abundance, and gradual decline, right up to destruction, makes it possible to define Stepnova's novel as a family chronicle. By introducing historical figures (Alexander III, the Ulyanov family, Blank), significant events (cholera riot), and references to Alexander Ulyanov in the final episode, the writer pushes the boundaries of the family chronicle genre, evoking the reader's memories of the historical transformations of the new era.

Keywords: family chronicle, garden, Russian world order, family theme, nobility, individuality, essential moments, 21st century Russian literature. 


\section{Использованная литература:}

1. Мякинина О. М., Шитуева И. А. Тема семьи и детства в современной русской литературе (по повести Павла Санаева «Похороните меня за плинтусом») // Культура. Духовность. Общество. Новосибирск. 2015. № 18. С. 36-41.

2. Ничипоров И. Б. Детство как травма в современной русской литературе (повесть Павла Санаева «Похороните меня за плинтусом») // Art Logos. 2019. № 1 (6). C. 47-52.

3. Осьмухина О. Ю. Специфика воплощения темы детства в прозе Л. Улицкой // Вестник Нижегородского университета им. Н. И. Лобачевского. 2014. № 6. С. 227231.

4. Осьмухина О. Ю., Казачкова А. В. Специфика воплощения «Детской» темы в современной отечественной прозе: многообразие рефлективных практик // Вестник Ленинградского государственного университета им. А. С. Пушкина. Сер.: Языкознание и литературоведение. 2012. Т. 1. № 4. С. 47-55.

5. Седашова Е. С. Жанр семейной саги в современной отечественной прозе // Символ науки. 2021. № 5 . С. 81-82.

6. Степнова М. Л. Сад. М.: АСТ. 2020.

7. Strong J. Hebrew and Khaldee Dictionary // The Exhaustive Concordance of the Bible. New York: Hunt \& Eaton; Cincinnati: Cranston \& Curts, 1890. P. 41.

\section{References:}

1. Myakinina, O.M \& Shitueva, I.A. (2015) Tema sem'i i detstva v sovremennoy russkoy literature (po povesti Pavla Sanaeva "Pokhoronite menya za plintusom") [The Theme of Family and Childhood in Modern Russian Literature (Based on Pavel Sanaev's "Bury Me Behind the Skirting Board")]. Kul'tura. Dukhovnost'. Obshchestvo. 18. pp. 36-41.

2. Nichiporov, I.B. (2019) Childhood as a Mental Trauma in Modern Russian Literature (The Novel by Pavel Sanaev "Bury Me Behind the Skirting Board"). Art Logos. 1 (6). pp. 47-52. (In Russian).

3. Os'mukhina, O.Yu. (2014) Specific Features of the Embodimentof the Childhood Theme in L. Ulitskaya's Prose. Vestnik Nizhegorodskogo universiteta im. N.I. Lobachevskogo - Vestnik of Lobachevsky University of Nizhni Novgorod. 6. pp. 227-231. (In Russian).

4. Os'mukhina, O.Yu. \& Kazachkova, A.V. (2012) Specific Character of an Embodiment of a "Children's" Subject in the Modern Domestic Prose: Variety Reflection an Expert. Vestnik Leningradskogo gosudarstvennogo universiteta im. A. S. Pushkina - Pushkin Leningrad State University Journal. 1 (4). pp. 47-55. (In Russian).

5. Sedashova, E.S. (2021) Zhanr semeynoy sagi v sovremennoy otechestvennoy proze [The Genre of the Family Saga in Modern Domestic Prose]. Simvol nauki. 5. pp. 81-82.

6. Stepnova, M.L. (2020) Sad [Garden]. Moscow: AST.

7. Strong, J. (1890) The Exhaustive Concordance of the Bible. New York: Hunt \& Eaton; Cincinnati: Cranston \& Curts. p. 41.

\section{Полная библиографическая ссылка на статью:}

Резник О. В. «Мысль семейная» как жанрообразующая категория в эпическом наследии Марины Степновой (на примере романа «Сад») / О. В. Резник // Наследие веков. - 2021. - № 4. - C. 79-84. DOI: 10.36343/SB.2021.28.4.005 of the Novel Garden). Nasledie vekov - Heritage of Centuries. 4. pp. 79-84. (In Russian). DOI: 10.36343/SB.2021.28.4.005 